\title{
ORIGINAL
}

\section{Effect of prolonged hospitalization on fetal growth in threatened preterm labor}

\author{
Maki Shibata, Takashi Kaji, Naoto Yonetani, Atsuko Yoshida, Eishi Sogawa, Kazuhisa Maeda, Minoru Irahara \\ Department of Obstetrics and Gynecology, Institute of Health Biosciences, the University of Tokushima Graduate School, Tokushima, Japan
}

\begin{abstract}
Objective : We aimed to demonstrate the effect of prolonged hospitalization on fetal growth in cases of threatened preterm labor (TPL). Methods : In this retrospective cohort study, we included women who received prenatal care for TPL but delivered their child after 36 weeks of gestation. These were compared with a control group of healthy pregnant women and fetuses delivered at term. Fetal growth was compared using biparietal diameter, abdominal circumference (AC), femur length, and estimated fetal weight (EFW) assessed using ultrasonography at 18, 26, 30, and 36 weeks of gestation. Neonatal parameters at birth were also compared. Results : In total, we enrolled 228 control women and 114 women with TPL who were treated with hospitalization, including bed rest. The AC at 30 and 36 weeks of gestation and EFW at 36 weeks of gestation were smaller in women treated with bed rest than for normal pregnant women. The mean duration of pregnancy was shorter in the hospitalization group than in the control group. Neonatal weight, length, head circumference, and chest circumference at birth were smaller after prolonged hospitalization for TPL than after normal pregnancy. Conclusion : Prolonged hospitalization for threatened preterm labor is associated with impaired fetal growth, particularly AC. J. Med. Invest. 66 : 153-156, February, 2019
\end{abstract}

Keywords : fetal growth, prolonged hospitalization, bed rest, threatened preterm labor

\section{INTRODUCTION}

Preterm birth, defined as birth prior to 37 weeks of gestation, affects $5 \%-18 \%$ of pregnancies and is the leading cause of neonatal mortality and morbidity (1-2). Inpatient bed rest is widely used to prevent preterm birth in women with threatened preterm labor (TPL) in Japan. Prolonged bed rest can induce muscle metabolism (3), increase bone turnover (4), thrombosis (5-6), weight loss (7), depressive symptoms (8-9), and other important symptoms in pregnant women. Based on not only its side effects, but also the lack of clear efficacy in the prevention of preterm delivery, the American Congress of Obstetricians Gynecologists (ACOG) states that bed rest is not prescribed routinely for preventing preterm birth (10).

In contrast, only a few studies have been conducted to evaluate the effect of prolonged hospitalization on fetuses. Maloni et al have reported that neonates born to mothers with bed rest weigh significantly less than the national mean (7). They, however, included pregnant women with various diseases, such as TPL, premature rupture of membranes, placenta previa, and abruption. Therefore, the diseases that mothers had, and not bed rest, might have affected the neonatal weight.

Recently, we discovered that women treated with prolonged hospitalization for TPL had lower serum 25-hydroxyvitamin D (25 $(\mathrm{OH}) \mathrm{D})$ concentrations in the third trimester than those in the normal control group (11). Fetal bone growth and birth weight was lower among infants of mothers deficient in vitamin $\mathrm{D}$ than in their

Received for publication October 4, 2018 ; accepted December 26, 2018.

Address correspondence and reprint requests to Maki Shibata, Department of Obstetrics and Gynecology, Institute of Health Biosciences, the University of Tokushima Graduate School, Tokushima 770-8503, Japan and Fax : +81-88-631-2630. replete peers $(12-14)$. Therefore, prolonged hospitalization during pregnancy for TPL was considered to affect fetal growth, particularly the bone length. However, fetal growth during maternal bed rest remains unclarified.

In this study, we aimed to elucidate the effect of prolonged hospitalization for TPL on fetal growth by assessing ultrasonographic in-utero parameters.

\section{SUBJECTS AND METHODS}

This retrospective study was conducted between January 2011 and December 2016 at Tokushima University hospital. The cohort comprised Japanese women with singleton pregnancies, those who received prenatal care, those who delivered after 36 weeks of gestation, and those who were admitted in the hospital for more than 28 consecutive days to manage TPL. Cases with regular objective uterine contractions and/or significant cervical changes (dilation and/or effacement) were diagnosed as TPL. They were admitted to reduce uterine contractions and prolong the pregnancy. Antepartum bed rest treatment with ambulation restricted only to bathroom privileges was prescribed. Intravenous ritodrine hydrochloride was administered as first-line tocolytic agent. Magnesium sulfate was used for women who continued to have symptomatic uterine contractions after the highest dose of ritodrine hydrochloride or for those who were not administered ritodrine hydrochloride because of adverse effects. The nutritional content of the meals provided to pregnant women admitted in the hospital included 626 $\mathrm{mg}$ of calcium, $1145 \mathrm{mg}$ of phosphorus, $7 \mu \mathrm{g}$ of vitamin D, and 2000 $\mathrm{kcal} /$ day on an average. These were compared with a control group of women who were not admitted for rest and who were matched by delivery season, maternal age, and pre-pregnancy body mass index. We excluded women who had multiple pregnan- 
cies, carbohydrate metabolism disorders, hypertensive disorders of pregnancy, autoimmune disease, or receiving antenatal corticosteroid from the study cohort.

The following maternal parameters were collected : age at delivery, parity, height, body weight before pregnancy, body mass index before pregnancy, smoking status, season at delivery, weeks of pregnancy at delivery, and body weight gain during pregnancy. In addition, the following neonatal parameters were collected: birth weight, birth length, head circumference, chest circumference, sex, Apgar scores at 1 and $5 \mathrm{~min}$, and $\mathrm{pH}$ and base excess of the umbilical artery at delivery. Fetal growth was measured and compared by the fetal biparietal diameter (BPD), abdominal circumference (AC), femur length (FL), and estimated fetal weight (EFW) assessed using ultrasonography at 18, 26, 30, and 36 weeks of gestation. EFW was calculated using the formula $1.07 \times$ $\mathrm{BPD}^{3}+0.30 \times \mathrm{AC}^{2} \times \mathrm{FL}(15)$. The study was approved by our institutional review board.

All data are expressed as mean \pm standard deviation. Statistical analysis of differences between groups was performed using the IBM SPSS software package and $\mathrm{P}$ values $<0.05$ were considered statistically significant.

\section{RESULTS}

In total, 114 cases and 228 matched controls were enrolled in this study. The maternal baseline characteristics and pregnancy outcomes are summarized in Table 1 . There were no significant differences in maternal baseline characteristics between the two groups. However, the mean duration of pregnancy was significantly $(p<0.01)$ shorter in the hospitalization group (37.6 \pm 1.4 weeks) than in the control group $(39.0 \pm 1.1$ weeks). Maternal weight gain during pregnancy was also less in the hospitalization group (5.2 \pm $9.1 \mathrm{~kg})$ than in the control group $(9.1 \pm 10.1 \mathrm{~kg})$. Women in the hospitalization group were admitted at $26.0 \pm 4.0$ weeks, and the duration of hospitalization was $68.4 \pm 26.6$ days. All pregnant women were treated with intravenous ritodrine hydrochloride and/ or magnesium sulfate (ritodrine hydrochloride : 95 women, magnesium sulfate : 1 woman, ritodrine hydrochloride and magnesium sulfate : 18 women).

Figure 1 shows the results for fetal growth at 18, 26, 30, and 36 weeks of gestation. As shown, AC at 30 and 36 weeks of gestation and EFW at 36 weeks of gestation were significantly smaller in the hospitalization group than in the control group (24.74 \pm 1.22 vs $25.23 \pm 1.86 \mathrm{~cm}, \mathrm{p}=0.03 ; 29.44 \pm 1.45$ vs $30.05 \pm 1.75 \mathrm{~cm}, \mathrm{p}<$ 0.01 ; and $2441.39 \pm 260.25$ vs $2535.93 \pm 294.12 \mathrm{~g}, \mathrm{p}<0.01$, respectively), whereas there were no differences in BPD and FL throughout the study period.

Overall, neonatal weight, length, head circumference, and chest circumference at delivery were significantly smaller in the hospitalization group than in the control group $(\mathrm{p}=0.01, \mathrm{p}=0.01, \mathrm{p}=$ 0.02 , and $\mathrm{p}=0.01$, respectively). However, the Apgar scores, as well as the $\mathrm{pH}$ and base excess of the umbilical cord arteries, were comparable between the groups.

\section{DISCUSSION}

We demonstrated that $\mathrm{AC}$ and $\mathrm{EFW}$ in the third trimester of fetuses in women hospitalized for TPL were smaller than in normal pregnant women. To our knowledge, this is the first study showing adverse effect of prolonged hospitalization on in-utero fetal growth in TPL.

We previously reported that, compared with control groups,

Table 1 Baseline characteristics and outcomes of patients in the study

\begin{tabular}{|c|c|c|c|}
\hline $\begin{array}{r}\text { Variables } \\
\end{array}$ & Subject $(\mathrm{n}=114)$ & Control $(\mathrm{n}=228)$ & $\mathrm{P}$ \\
\hline \multicolumn{4}{|l|}{ Maternal characteristics } \\
\hline Age at delivery (years) & $32.5 \pm 4.7$ & $32.7 \pm 5.2$ & 0.71 \\
\hline Nulliparity (\%) & 48.2 & 47.8 & 0.94 \\
\hline Body height (cm) & $158.0 \pm 6.2$ & $157.3 \pm 5.4$ & 0.27 \\
\hline Body weight before pregnancy (kg) & $52.7 \pm 9.1$ & $52.6 \pm 11.8$ & 0.94 \\
\hline BMI before pregnancy $(\mathrm{kg} / \mathrm{m} 2)$ & $21.1 \pm 3.0$ & $21.2 \pm 4.4$ & 0.74 \\
\hline Rate of smoking (\%) & 0 & 1.8 & 0.12 \\
\hline \multicolumn{4}{|l|}{ Seasonal calendar quarter at delivery } \\
\hline Spring & $30(26.3)$ & $60(26.3)$ & \\
\hline Summer & $37(32.5)$ & $74(32.5)$ & \\
\hline Autumn & $22(19.3)$ & $44(19.3)$ & \\
\hline Winter & $25(21.9)$ & $50(21.9)$ & \\
\hline \multicolumn{4}{|l|}{ Labor outcome } \\
\hline Weeks of pregnancy at delivery (weeks) & $37.6 \pm 1.4$ & $39.0 \pm 1.1$ & $<0.01$ \\
\hline Body weight gain $(\mathrm{kg})$ & $5.2 \pm 9.1$ & $9.1 \pm 10.1$ & $<0.01$ \\
\hline \multicolumn{4}{|l|}{ Neonatal outcomes } \\
\hline Birth weight (g) & $2828.4 \pm 449.1$ & $3050.4 \pm 365.0$ & $<0.01$ \\
\hline Birth length $(\mathrm{cm})$ & $48.5 \pm 2.3$ & $49.5 \pm 1.9$ & $<0.01$ \\
\hline head circumference $\quad(\mathrm{cm})$ & $32.9 \pm 1.5$ & $33.3 \pm 1.4$ & 0.02 \\
\hline chest circumference $(\mathrm{cm})$ & $30.9 \pm 1.9$ & $32.0 \pm 1.6$ & $<0.01$ \\
\hline Boys (\%) & $56(44.7)$ & $122(49.2)$ & 0.45 \\
\hline Apgar score at $1 \mathrm{~min}$ & $8.0 \pm 1.1$ & $8.2 \pm 0.8$ & 0.05 \\
\hline Apgar score at 5 min & $9.1 \pm 0.5$ & $9.1 \pm 0.6$ & 0.55 \\
\hline $\mathrm{pH}$ of umbilical cord artery blood & $7.30 \pm 0.06$ & $7.30 \pm 0.15$ & 0.47 \\
\hline BE of umbilical cord artery blood & $-4.71 \pm 2.76$ & $-4.93 \pm 2.92$ & 0.51 \\
\hline
\end{tabular}


Table 2 Hospitalization data for women admitted with threatened preterm labor

\begin{tabular}{lc}
\hline Variables & $\begin{array}{c}\text { Mean } \pm \\
\text { standard } \\
\text { deviation }\end{array}$ \\
\hline Gestational age on admission (weeks) & $26.0 \pm 4.0$ \\
Duration of hospitalization & $68.4 \pm 26.6$ \\
Treatment contents & 95 \\
Intravenous ritodrine hydrochloride & 1 \\
Intravenous magnesium sulfate & 18 \\
Intravenous ritodrine hydrochloride + magnesium sulfate & \\
\hline
\end{tabular}

serum $25(\mathrm{OH}) \mathrm{D}$ concentration are lower in mothers treated with hospitalization for TPL (11). Some authors have reported that maternal low 25(OH)D levels were associated with impaired fetal bone growth and birth weight $(12-14,16)$. Consequently, we predicted that FL would be shorter and birth weight would be lesser in the hospitalization for TPL group than after standard care for normal pregnancies. However, there were no significant differences in either FL or BPD between the groups, whereas AC and EFW were smaller in the group treated with prolonged hospitalization. $\mathrm{AC}$ mainly represents soft tissue growth and is a more sensitive marker for fetal growth than is BPD (which mainly represents brain development) and FL (which represents skeletal development) (17). Ioannou et al. reported that fetal femoral volume and femoral proximal metaphyseal diameter were positively associated with maternal 25(OH)D (18). Moreover, Vitamin D affects both bone resorption and formation (19), then the lack of vitamin D cause calcification failure of the bone (20). Based on the above, the width and/or quality of fetal bone might be more affected than length by low maternal Vitamin D.

Neonates delivered to women with prolonged hospitalization for TPL were smaller than those delivered to women in the control group, having smaller weights, lengths, head circumferences, and chest circumferences. It was difficult to say that prolonged hospitalization for TPL cause differences between neonates because neonates in the hospitalization group were born at an earlier gestational age than those in the control group. However, we followed fetal growth using ultrasound since before hospitalization not only at birth. There was no difference of fetal growth between the two groups before hospitalization or early during the hospitalization (18 and 26 weeks of gestation), but AC at 30 and 36 weeks of gestation and EFW at 36 weeks of gestation were smaller in the group with prolonged hospitalization. Therefore, we assumed that prolonged hospitalization, including bed rest, adversely affects fetal growth.

The possible cause other than low maternal vitamin $\mathrm{D}$ level for smaller AC, EFW, and smaller neonates for the hospitalization group is less maternal weight gain in the hospitalization group than in the control group. In the study conducted by Maloni et al, neonatal birth weight and maternal weight gain in pregnant women treated with bed rest for various diseases were significantly lower than their matched controls, including gestational age at birth (7). Birth weight is positively related to the maternal weight gain. Therefore, maternal weight gain itself might impair fetal growth.

The use of preterm labor treatment may also affect fetal growth in the hospitalization group. Ritodrine hydrochloride is a $\beta$-adrenergic stimulator, which thereby increases metabolism. Furthermore, magnesium sulfate prevents calcium influx into cells depolarization at the cell membrane. FDA states that magnesium sulfate may lead to low calcium levels and bone breaks (21), which could affect fetal growth.

This study has some limitations. First, the dietary intake of mothers in both groups was not established. In the TPL group individual dietary intake was not monitored, although a calculated meal was served. Women in the TPL group were less active, so their appetite might have reduced and caused insufficient food intake. Moreover, dietary intake in control group was not assessed. Second, there were no data about vitamin D intake or levels,
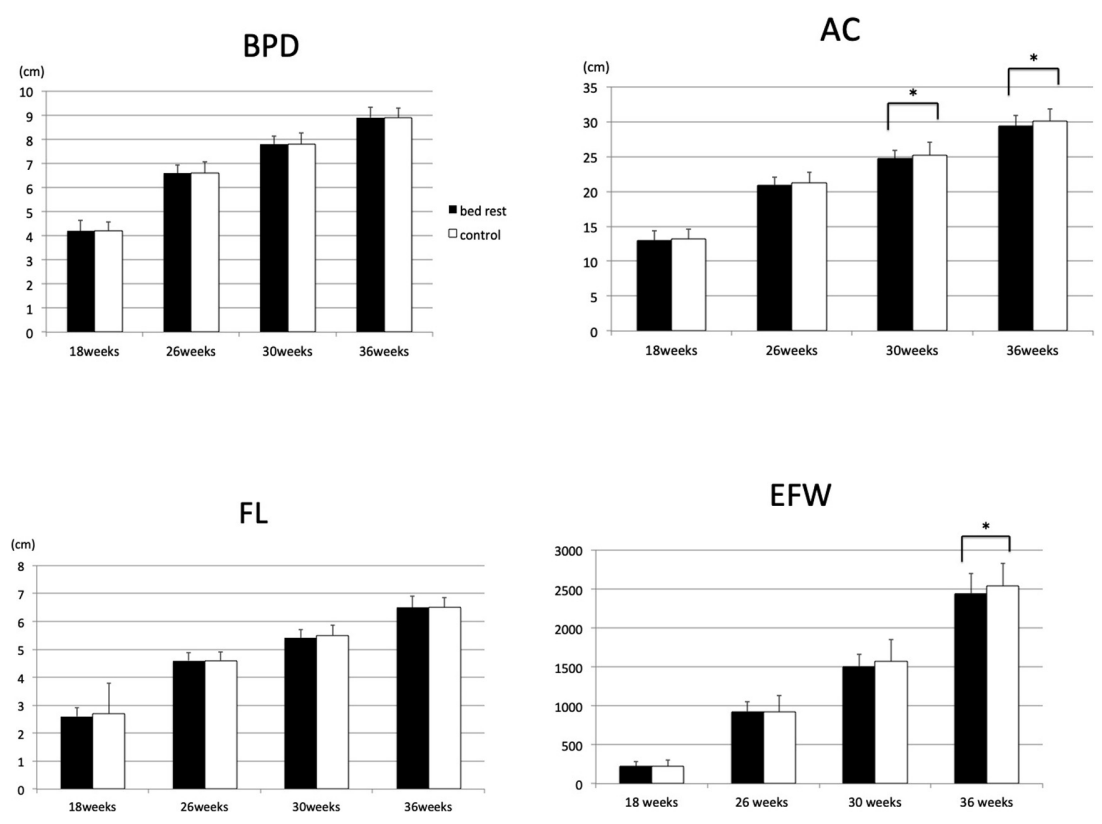

Figure 1. Comparison of $\mathrm{BPD}, \mathrm{AC}, \mathrm{FL}$, and $\mathrm{EFW}$ as fetal growth parameters between normal pregnant women and women treated with bed rest for threatened premature delivery

Fetal growth was assessed by the fetal biparietal diameter (BPD), abdominal circumference (AC), femur length (FL), and estimated fetal weight (EFW) at 18, 26, 30, and 36 weeks of gestation. Closed bar : pregnant women with bed rest for threatened premature delivery. ${ }^{*} \mathrm{p}<0.05$ 
which is important considering the knowledge that vitamin D levels affect fetal growth. Third, our study was retrospective and relatively small scale.

Although $\mathrm{AC}$ and EFW were smaller in women with prolonged hospitalization for TPL than those in normal pregnant women, we do not know whether these differences affect neonatal prognosis, child development, or other risks. Low birth weight increases the risk of developmental disorders, short stature, impaired hearing, and epilepsy in childhood (22-23). Even after becoming an adult, it increases cardiovascular diseases, non-insulin-dependent diabetes, and hypertension (24-25). Thus, we need to examine long-term prognosis of neonates born to mothers with TPL.

In conclusion, our study shows that prolonged hospitalization for TPL is associated with an impaired growth, of AC and EFW in the third trimester. Treatment for TPL can adversely affect fetal growth.

\section{CONFLICT OF INTEREST}

There are no conflicts of interest to declare.

\section{REFERENCES}

1. Ministry of Health Labour and Welfare : Vital statistics in Japan

2. Liu L, Johnson HL, Cousens S, Perin J, Scott S, Lawn JE, Rudan I, Campbell H, Cibulskis R, Li M, Mathers C, Black RE : Global, regional, and national causes of child mortality : an updated systematic analysis for 2010 with time trends since 2000. Lancet $379: 2151-2161,2012$

3. Maloni JA, Schneider BS. Inactivity : symptoms associated with gastrocnemius muscle disuse during pregnancy. AACN Clin Issues $13:$ 248-262, 2002

4. Kaji T, Yasui T, Suto M, Mitani R, Morine M, Uemura H, Maeda H, Irahara M. Effect of bed rest during pregnancy on bone turnover markers in pregnant and postpartum women. Bone 40 : 1088-1094, 2007

5. Kovacevich GJ, Gaich SA, Lavin JP, et al. The prevalence of thromboembolic events among women with extended bed rest prescribed as part of the treatment for premature labor or preterm premature rupture of membranes. Am J Obstet Gynecol 182 : 1089-1092, 2000

6. Danilenko-Dixon DR, Heit JA, Silverstein MD, et al. Risk factors for deep vein thrombosis and pulmonary embolism during pregnancy or post partum : a population-based, casecontrol study. Am J Obstet Gynecol 184 : 104-110, 2001

7. Maloni JA, Alexander GR, Schluchter MD, Shah DM, Park S. Antepartum bed rest : maternal weight change and infant birth weight. Biol Res Nurs 5 : 177-186, 2004

8. Fortney SM, Schneider VS, Greenleaf JE. The physiology of bed rest. In : Fregley MJ, Blatteis CM, editors. Handbook of physiology. NY, USA : Oxford University Press ; 1989.

9. Measurement of antepartum depressive symptoms during high-risk pregnancy. Res Nurs Health 28 : 16-26, 2005

10. Management of preterm labor. Clinical management guidelines for obstetrician-gynecologists. ACOG 2016 ; Number 171.

11. Yonetani N, Kaji T, Hichijo A, Nakayama S, Maeda K, Irahara M. Effect of prolonged hospitalization for threated preterm labor on maternalk and fetal vitamin D levels. J Obstet Gynecol Res $44: 1042-1048,2018$

12. Bowyer L, Catling-Paull C, Diamond T, Homer C, Davis G, Craig ME. Vitamin D, PTH and calcium levels in pregnant women and their neonates. Clin Endocrinol 70 : 372-377, 2009

13. Young BE, McNanley TJ, Cooper EM, McIntyre AW, Witter F, Harris ZL, O'Brien KO. Maternal vitamin D status and calcium intake interact to affect fetal skeletal growth in utero in pregnant adolescents. Am J Clin Nutr 95 : 1103-1112, 2012

14. Galthen-Sorensen M, Andersen LB, Sperling L, Christesen HT. Maternal 25-hydroxyvitamin D level and fetal bone growth assessed by ultrasound : a systematic view. Ultrasound Obstet Gynecol 44 : 633-640, 2014

15. Shinozuka N, Okai T, Kohzuma S, Mukubo M, Shih CT, Maeda T, Kuwabara Y, Mizuno M. Formulas or Fetal Weight Estimation by Ultrasound Measurements Based on Neonatal Specific Gravities and Volumes. Am J Obstet Gynecol 157 : 1140-1145, 1987

16. Dijkstra SH, van Beek A, Janssen JW, de Vleeschouwer LH, Huysman WA, van den Akker EL. High prevalence of vitamin D deficiency in newborn infants of high-risk mothers. Arch Dis Child 92 : 750-753, 2007

17. Hadlock FP, Deter RL, Harrist RB, Roecker E, Park SK. A dateindependent predictor of intrauterine growth retardation : femur length/ abdominal circumference ratio. Am J Roentgenol $141: 979-984,1983$

18. Inannou C, Javaid MK, Mahon P, Yaqub MK, Harvey NC, Godfrey KM, Noble JA, Cooper C, Papageorghiou AT. The effect of maternal vitamin D concentrateon on fetal bone.J Clin Endocrinol Metab 97 : 2070-2077, 2012

19. Nakae M, Fey TA, Dixon DB, Ma J, Brune ME, Li YC, Wuwong JR. Differential dffects of vitamin D analogs on bone formation and resorption. J Seroid Biochem 98 : 72-77, 2006

20. Bikle D. Vitamin D : Production, metabolism, and Mechanisms of Action. Endotext. 2017

21. FDA recommends against prolonged use of magnesium sulfate to stop pre-term labor due to bone changes in exposed babies. FDA Drug Safety Communications, 2013

22. Llurba E, Baschat AA, Turan OM, Harding J, McCowan LM. Childhood cognitive development after fetal growth restriction. Ultrasound Obstet Gynecol 41 : 383-389, 201324

23. Frisancho AR, Fields S, Smith SL. Small for gestational age associated with short stature during adolescence. AmJ Hum Bio 6 : 305-309, 1994

24. Osmond C, Barker DJ, Winter PD, Fall CH, Simmonds SJ. Early growth and death from cardiovascular disease in women. BMJ 307 : 1519-1524, 1993

25. Phipps K, Barker DJ, Hales CN, Fall CH, Osmond C, Clark PM. Fetal growth and impaired glucose tolerance in men and women. Diabetologia 36 : 225-228, 1993 